\section{Estudo etiológico da diarréia em crianças hospitalizadas no Instituto Materno Infantil Prof. Fernando Figueira, IMIP, em Recife, Pernambuco}

\author{
Etiological study of diarrhea in children \\ hospitalized at Instituto Materno Infantil \\ Prof. Fernando Figueira, IMIP, in Recife, \\ Pernambuco
}

João Paulo de Souza Pontual 1

Ana Rodrigues Falbo 2

Josiana da Silva Gouveia3

1-3 Grupo de Estudos de Saúde da Criança. Departamento de Pesquisa. Instituto Materno Infantil Prof. Fernando Figueira, IMIP: Rua dos Coelhos 300. Recife, PE, Brasil. CEP: 50.070-550.

\begin{abstract}
Objectives: to identify enteropathogens in the stools of children hospitalized with diarrhea.

Methods: case series studies, comprising 36 children aged between zero and 60 months old with diarrhea hospitalized in the Instituto Materno Infantil Prof. Fernando Figueira, IMIP, between January and May, 2005. Social and demographic variables were collected, mothers'characteristics and diarrhea episode. Etiological research used stools culture and serologic tests.

Results: the majority of the children (80.5\%) were under 12 months old. Families had very poor social and economic conditions and $83.4 \%$ had per capita incomes under half a minimum salary per month. As for the microorganisms detected in stools culture, classis enteropathogenic E.coli (EPEC) appeared in $8.4 \%$ of the cases with no growth of Salmonella sp. or Shiguella sp. and Klebsiella sp. ESBL + was isolated in $33.3 \%$ of the patients. Klebisiellas demonstrated a high resistance profile in the antibiogram, compatible with hospital strains catalogued by the institution.

Conclusions: the study presented a low enteropathogenic bacteria recovery rate but revealed a prevalent mutiresistant Klebsiella strain with important nosocomial infection risk implications and diarrhea persistence.
\end{abstract}

Key words Infantile diarrhea, Intestinal diseases, Child Hospitalized

\section{Resumo}

Objetivos: identificar enteropatógenos nas fezes de crianças hospitalizadas com diarréia.

Métodos: estudo de série de casos, com a participação de 36 crianças entre zero a 60 meses, com diarréia, hospitalizadas no Instituto Materno Infantil Prof. Fernando Figueira, IMIP, no período entre janeiro e maio de 2005. Foram coletadas as variáveis sóciodemográficas, características das mães e do episódio diarréico. A pesquisa etiologica utilizou coprocultura e testes sorológicos.

Resultados: a maioria das crianças (80,5\%) tinha menos de 12 meses. As famílias tinham precárias condições socioeconômicas e 83,4\% tinha renda per capita inferior a meio salário mínimo/mês. Quanto aos microorganismos recuperados nas culturas de fezes, a $E$. coli enteropatogênica clássica (EPEC) apareceu em $8,4 \%$ dos casos, não havendo crescimento de Salmonella sp. ou Shiguella sp. e a Klebsiella sp. ESBL + foi isolada em 33,3\% dos pacientes. As Klebsiellas apresentaram um alto perfil de resistência no antibiograma, compatível com as cepas hospitalares catalogadas na instituição.

Conclusões: o estudo apresentou uma baixa taxa de recuperação de bactérias enteropatogênicas mas revelou uma prevalência de Klebsiella multirresistente, o que tem importantes implicações no risco de infecção hospitalar e persistência do episódio diarréico.

Palavras-chave Diarréia infantil, Enteropatias, Crianca hospitalizada 


\section{Introdução}

A doença diarréica da criança é, ainda nos dias correntes, uma síndrome freqüente, estando entre as principais causas de consulta, internação e letalidade, sobretudo em paises em desenvolvimento. ${ }^{1}$

No mundo, a doença diarréica é uma causa importante de morbidade e mortalidade em crianças menores de cinco anos, com 1,4 bilhões de episódios anuais. Desses casos, 1,29 bilhões necessitam de cuidados domiciliares, 124 milhões de visitas hospitalares, 9 milhões de hospitalizações e uma estimativa de 2,1 milhões de mortes ao ano. ${ }^{2}$

Bern et al. ${ }^{1}$ demonstraram a diarréia como uma importante doença infantil, sendo responsável por mais de $20,0 \%$ da mortalidade infantil em muitas áreas da américa latina.

O número total de mortes por diarréia ainda é excessivamente alto, mas houve uma redução substancial nas décadas de 80 e 90 com o advento da terapia de reidratação oral, implantada desde 1980, através do Programa de Controle da Doença Diarréica da World Health Organization (WHO). 3 Em 1982, havia uma estimativa de 5 milhões de mortes ao ano e em 1992, esta estimativa declinou para três milhões. ${ }^{2}$

Em 1999, a mortalidade proporcional por diarréia aguda em menores de cinco anos foi 5,5\% para todo o país, estando entre as cinco maiores causas. Essa mortalidade é elevada no Nordeste $(10,0 \%)$ e baixa no Sudeste $(2,7 \%) .4$

Segundo dados do Ministério da Saúde, a doença diarréica ocupa o segundo lugar entre as causas de hospitalização no Brasil. Em 1993, nas regiões Norte e Nordeste, era a primeira causa de internação, seguida da broncopneumonia. No ano de 2000, na região Norte, permanecia como primeira causa de hospitalização e segunda, no Nordeste. ${ }^{4}$

A diarréia pode ser classificada em aguda ou persistente. A diarréia aguda é definida como um processo sindrômico de duração igual ou inferior a 14 dias, de etiologia presumivelmente infecciosa (viral, bacteriana ou parasitária), que provoca má absorção de água e eletrólitos, aumento do número de evacuações e do volume fluido fecal, acarretando à criança depleção hidrossalina de intensidade variável. 5 Conceitualmente, a diarréia persistente representa um episódio diarréico de início abrupto de etiologia presumivelmente infecciosa, com duração superior a 14 dias e que repercute negativamente sobre o estado nutricional. 6

A diarréia aguda pode ser provocada por múltiplos agentes etiológicos, como bactérias, vírus e protozoários. Muitos estudos apontam o rotavírus como agente etiológico preponderante nos países desenvolvidos, enquanto as bactérias são mais importantes nas crianças de países em desenvolvimento.7-9 Esses dados, contudo, não são consensuais. Um estudo multicêntrico, em paises em desenvolvimento, promovido pela Organização Mundial da Saúde (OMS) demonstrou uma maior prevalência do rotavirus em crianças menores que 12 meses de idade e uma maior prevalência bacteriana no segundo e terceiro anos de vida. ${ }^{10}$ Existem ainda trabalhos realizados em locais com precárias condições socioeconômicas que apontam o rotavirus como agente patogênico mais freqüente em crianças abaixo de cinco anos. ${ }^{11,12}$

A maioria das infecções gastrintestinais, incluindo as de etiologia bacteriana, são autolimitadas. Por isso o manejo da diarréia baseia-se em dois aspectos principais: correção da hidratação e alimentação. Evitar a desidratação e manter um aporte adequado de nutrientes garantem uma recuperação mais rápida e a manutenção do crescimento da criança.6,14 São poucas as situações em que os antimicrobianos são efetivos no controle da diarréia e ademais seu uso pode trazer, além dos efeitos colaterais inerentes a cada droga, um desequilíbrio da microflora intestinal, facilitando o crescimento de enteropatógenos. 15

Apesar de não se encontrar unanimidade quanto à etiologia da doença diarréica em países em desenvolvimento, há nesses locais um grande número de fatores favorecendo a infecção bacteriana, tais quais: deficiências nutricionais, práticas inadequadas de higiene física e alimentar, desmame precoce, aglomerações no domicílio e institucionais, ausência de saneamento básico nos locais de permanência, acesso a coleções hídricas contaminadas. 13 Torna-se claro, portanto, a relevância desse agente em regiões como o Nordeste do Brasil.

Nessa região encontra-se o Instituto Materno Infantil Prof. Fernando Figueira (IMIP), que é Centro de Referência Nacional para a Assistência Materno-Infantil pelo Ministério da Saúde, presta assistência a uma média mensal de 30.954 pacientes de Pernambuco e de outros estados do Nordeste do Brasil, dos quais 1.692 são pediátricos. Em 2003 foram atendidas na emergência pediátrica cerca de 4800 crianças com diarréia, com $11 \%$ de hospitalização. 16

Tendo em vista o supracitado e a escassez das informações se faz importante a realização de estudos sobre a etiologia da diarréia no IMIP. Os resultados poderão contribuir não só para melhorar o conhecimento sobre essa doença, como também para adequar o seu manejo, diminuindo o impacto de um 
fator de risco tão importante como a diarréia para a morbimortalidade infantil

\section{Métodos}

Foi realizado um estudo de série de casos, do qual participaram 36 crianças com idade entre zero a 60 meses, apresentando diarréia, caracterizada pela presença de três ou mais dejeções de consistência diminuída num período de 24 horas ou pelo menos uma com sangue visível, hospitalizadas no IMIP, no período entre janeiro e maio de 2005 . Inicialmente foram selecionadas 45 crianças das quais nove foram excluídas, por não ser possível a realização da coprocultura.

Foram estudadas variáveis sócio-demográficas tais como: renda per capita, local de residência, condição da habitação (água encanada, fossa ou esgoto e recolhimento de lixo); variáveis maternas: idade, escolaridade, paridade, ocupação; variáveis para caracterização do episódio diarréico: tipo e duração. Quanto ao manejo foi avaliada a utilização de antibioticoterapia. Para o estudo da etiologia foi utilizada a realização da coprocultura.

A coleta dos dados foi feita por meio de um formulário construído conforme as variáveis do estudo para permitir o alcance dos objetivos propostos. O formulário foi aplicado ao acompanhante responsável pelo menor após o consentimento livre e esclarecido. As amostras fecais foram obtidas das crianças após evacuação espontânea. As fezes pastosas eram coletadas da fralda com uma paleta logo após a defecação e colocadas em um saco coletor. As fezes líquidas eram colhidas em saco coletor devidamente posicionado.

A pesquisa bacteriana foi realizada no Laboratório de Análises Clínicas e Toxicológicas do IMIP de acordo com a rotina da instituição, como se segue: foi utilizado o meio Teague SS (Salmonella e Shiguella), HE (Hektoen Entero-agar) enriquecido com tetrationato de sódio. As culturas foram avaliadas em 24 e 48 horas. As amostras identificadas bioquimicamente, como Salmonella $s p$. foram submetidas à aglutinação com anti-soro polivalente, flagelar e VI. As amostras identificadas bioquimicamente como Shigella $s p$. foram submetidas à aglutinação com anti-soros polivalentes, específicos para Shigella dysenteriae, Shigella flexneri, Shigella boydii e Shigella sonnei. Quanto à Escherichia coli, foi utilizada a técnica de aglutinação em lâmina a partir de uma suspensão bacteriana, para identificação dos sorogrupos das bactérias enteropatogênicas. As amostras identificadas bioquimica- mente como E. coli eram submetidas às provas de aglutinação em lâmina, com anti-soro polivalente contra sorogrupos clássicos de E. coli (EPEC) dos grupos A, B e C. O grupo A representa os sorogrupos $\mathrm{O}_{26}, \mathrm{O}_{55}, \mathrm{O}_{111}$ e $\mathrm{O}_{119}$. O grupo B é composto pelos sorogrupos $\mathrm{O}_{114}, \mathrm{O}_{125}, \mathrm{O}_{142}$ e $\mathrm{O}_{158}$. O grupo C pelos sorogrupos $\mathrm{O}_{86}, \mathrm{O}_{126}, \mathrm{O}_{127}$. Sorogrupos invasores de E. coli (EIEC) também foram pesquisados, sendo divididos em grupos A e B. O grupo A englobando os sorogrupos $\mathrm{O}_{28 \mathrm{ac}}, \mathrm{O}_{29}, \mathrm{O}_{136}, \mathrm{O}_{144}, \mathrm{O}_{152}$, e o grupo $\mathrm{B}$ os sorogrupos $\mathrm{O}_{112 \mathrm{ac}}, \mathrm{O}_{124}, \mathrm{O}_{143}, \mathrm{O}_{164}$ e $\mathrm{O}_{167}$.

O presente estudo foi aprovado pelo Comitê de Ética e Pesquisa em Seres Humanos do IMIP.

\section{Resultados}

Quanto às características das crianças, aproximadamente $60,0 \%$ eram do sexo masculino e $80,5 \%$ tinham idade inferior a 12 meses (Tabela 1). No geral, tinham precárias condições socioeconômicas com $83,4 \%$ das famílias apresentando renda per capita inferior a meio salário mínimo por mês. Quarenta e quatro por cento delas não possuíam água encanada, 19,4\% não possuíam fossa ou esgotamento sanitário e em $25,0 \%$ dos casos não havia recolhimento de lixo no domicílio (Tabela 2).

A Tabela 3 aponta que aproximadamente $80,0 \%$ das mães não tinham trabalho remunerado e $94,5 \%$ tinham menos de oito anos de escolaridade.

Quanto à duração do episodio diarréico 86,1\% dos casos foram agudos e $16,7 \%$ apresentaram sangue visível nas fezes (Tabela 4). Das 36 crianças

Tabela 1

Distribuição de frequência das crianças com diarréia hospitalizadas segundo sexo e idade. Instituto Materno Infantil Prof. Fernando Figueira, IMIP, Recife,

Pernambuco, 2005.

\begin{tabular}{lcc}
\hline Variáveis & $\mathbf{N}(36)$ & $\%$ \\
\hline Sexo & 21 & \\
Masculino & 15 & 58,3 \\
Feminino & & 41,7 \\
& & \\
Idade & 18 & \\
$0-6$ & 11 & 50,0 \\
$7-12$ & 3 & 30,5 \\
$13-24$ & 2 & 8,3 \\
$25-36$ & 2 & 5,5 \\
$37-60$ & & 5,5 \\
\hline
\end{tabular}


analisadas, 33 utilizaram antibioticoterapia durante a hospitalização. As drogas usadas estão listadas na Tabela 5. Aproximadamente $70,0 \%$ das crianças já estavam em uso de antibiótico há pelo menos 24 horas no momento da coleta da amostra fecal.

Quanto aos microorganismos recuperados nas culturas de fezes, a $E$. coli enteropatogênica clássica (EPEC) apareceu em três dos casos, não houve crescimento de Salmonella sp. ou Shiguella sp. e a Klebsiella $s p$. ESBL + foi isolada em 33,3\% dos pacientes (Tabela 6). Dentre as 12 crianças que apresentaram Klebsiella sp. ESBL+ na coprocultura, 6 estavam no terceiro dia de internamento quando a cultura foi solicitada, 2 estavam no quarto dia, 3 estavam no quinto e 1 estava no $18^{\circ}$ dia.

Tabela 2

Distribuição de freqüência das crianças com diarréia hospitalizadas, segundo algumas características sociodemográficas. Instituto Materno Infantil Prof. Fernando Figueira, IMIP. Recife, Pernambuco, 2005.

\begin{tabular}{|c|c|c|}
\hline Variáveis & $N(36)$ & $\%$ \\
\hline \multicolumn{3}{|l|}{ Renda per capita* } \\
\hline$<R \$ 75,00(1 / 4 S M) * *$ & 15 & 41,7 \\
\hline$R \$ 75,00$ a $R \$ 150,00$ & 15 & 41,7 \\
\hline$\geq R \$ 150,00$ & 2 & 5,6 \\
\hline \multicolumn{3}{|l|}{ Local de residência } \\
\hline Região Metropolitana do Recife & 20 & 55,6 \\
\hline Zona da Mata & 10 & 27,8 \\
\hline Agreste & 5 & 13,9 \\
\hline Sertão & 0 & 0,0 \\
\hline Vale do São Francisco & 1 & 2,8 \\
\hline \multicolumn{3}{|l|}{ Água encanada } \\
\hline $\operatorname{Sim}$ & 20 & 55,6 \\
\hline Não & 16 & 44,4 \\
\hline \multicolumn{3}{|l|}{ Fossa ou esgoto } \\
\hline Sim & 29 & 80,6 \\
\hline Não & 7 & 19,4 \\
\hline \multicolumn{3}{|l|}{ Recolhimento de lixo* } \\
\hline Sim & 25 & 69,4 \\
\hline Não & 9 & 25,0 \\
\hline
\end{tabular}

*A não correspondência da porcentagem com o total da amostra se deve à falta de informação em um ou mais formulários pesquisados. ** SM = Salário mínimo

\section{Tabela 3}

Distribuição de freqüência das crianças com diarréia hospitalizadas, segundo algumas características das mães. Instituto Materno Infantil Prof. Fernando Figueira, IMIP. Recife, Pernambuco, 2005.

\begin{tabular}{lrr}
\hline Variáveis & N (36) & $\%$ \\
\hline Idade em anos & & \\
$<19$ & 29 & 8,3 \\
19 a 30 & 4 & 11,1 \\
$\geq 30$ & & \\
Escolaridade* & 6 & 16,7 \\
Nenhuma & 28 & 77,8 \\
$<8$ anos & 1 & 2,8 \\
$\geq 8$ anos & & \\
Paridade & 9 & 25,0 \\
1 a 2 filhos & 16 & 44,5 \\
2 a 4 filhos & 11 & 30,5 \\
$\geq 4$ filhos & & \\
Ocupação & & \\
Trabalha no lar sem remuneração & 28 & 77,8 \\
Trabalho remunerado & 8 & 22,2 \\
\hline
\end{tabular}

*A não correspondência da porcentagem com o total da amostra se deve à falta de informação em um ou mais formulários pesquisados.

\section{Tabela 4}

Distribuição de frequência das crianças com diarréia, segundo características do episodio diarréico. Instituto Materno Infantil Prof. Fernando Figueira, IMIP. Recife, Pernambuco, 2005.

\begin{tabular}{lrc}
\hline Variáveis & N (36) & $\%$ \\
\hline Duração & & \\
$<14$ dias & 31 & 86,1 \\
$\geq 14$ dias & 5 & 14,9 \\
Tipo* & 29 & \\
Aquosa & 60,6 \\
Disenteria & 6 & 16,7 \\
\hline
\end{tabular}

*A não correspondência da porcentagem com o total da amostra se deve à falta de informação em um ou mais formulários pesquisados. 
Tabela 5

Distribuição de frequência das crianças com diarréia hospitalizadas, segundo o uso de antibióticos. Instituto Materno Infantil Prof. Fernando Figueira, IMIP. Recife, Pernambuco, 2005.

\begin{tabular}{lrr}
\hline Fármacos* & N (33) & $\%$ \\
\hline Acido nalidíxico & 4 & 11,7 \\
Amoxacilina & 8 & 23,5 \\
Ampicilina & 14 & 41,2 \\
Penicilina G & 5 & 14,7 \\
Oxacilina & 4 & 11,7 \\
Gentamicina & 15 & 44,1 \\
Amicacina & 4 & 11,7 \\
Cefalexina & 2 & 5,9 \\
Cefalotina & 3 & 8,8 \\
Ceftriaxona & 10 & 29,4 \\
Cloranfenicol & 2 & 5,9 \\
Meropenem & 4 & 11,7 \\
\hline
\end{tabular}

* Muitas crianças fizeram uso de esquemas combinados e antimicrobianos.

\section{Tabela 6}

Distribuição de frequência das crianças com diarréia hospitalizadas, segundo resultado de coproculturas. Instituto Materno Infantil Prof. Fernando Figueira, IMIP. Recife, Pernambuco, 2005.

\begin{tabular}{lcc}
\hline Etiologia & N (33) & $\%$ \\
\hline EPEC & 3 & 8,4 \\
Salmonella & 0 & 0,0 \\
Shiguella & 0 & 0,0 \\
Klebsiella sp. ESBL+ & 12 & 33,3 \\
Microflora bacteriana normal & 21 & 58,3 \\
\hline
\end{tabular}

*EPEC $=\mathrm{E}$. coli enteropatogênica clássica

\section{Discussão}

Como foram estudadas crianças hospitalizadas em um hospital terciário voltado para os usuários do Sistema Única de Saúde (SUS) era de se esperar que esse grupo apresentasse características sociodemográficas semelhantes às referidas na literatura para crianças com a mesma condição, ou seja, com a presença de diarréia e morando numa região pobre. ${ }^{1-4}$ De fato, a maior parte das crianças tinha idade inferior a 12 meses, com mais de $80,0 \%$ das famílias vivendo abaixo da linha de pobreza e mais de $90,0 \%$ das mães com menos de oito anos de escolaridade.
Foram identificadas bactérias enteropatogênicas clássicas em $8,4 \%$ das culturas. O único agente isolado foi a EPEC. Shiguella e Salmonella e outras cepas de $E$. coli não foram identificadas. Este percentual de recuperação é inferior ao descrito na literatura. Um estudo multicêntrico realizado pela OMS em paises em desenvolvimento obteve $48,0 \%$ de recuperação bacteriana em 3640 amostras fecais de crianças com diarréia. A $E$. coli foi o agente mais prevalente com $16,0 \%$ de $E$. coli enterotoxigênica (ETEC) e 9,0\% de EPEC, a Shiguella spp. e a Campilobacter jejuni, cada uma aparecendo em $11,0 \%$ das amostras. A Salmonella spp. ocorreu em 3,0\% das análises. ${ }^{10}$ Maraki et al. 17 analizaram 7090 amostras fecais e isolaram um ou mais enteropatógenos em 14,0\%.A Salmonella sp. foi detectada em 6,0\%, seguida pela Campylobacter $s p$. $(4,2 \%)$ e pela EPEC com 1,8\%. A Yersinia enterocolitica, a Shiguella spp. e a Aeromonas hydrophila foram pouco freqüentes, aparecendo, cada uma, em menos de 1,0\% das amostras. Souza et al. 7 estudaram 154 crianças com diarréia aguda em São Paulo, recuperando um agente bacteriano em 34,4\% dos casos. A E. coli foi o agente mais freqüente, encontrado em 65 crianças das quais 25 foram EPEC e 19 ETEC, a Shiguella em 19, a Salmonella em duas e a $Y$. enterocolitica em uma criança.

No presente estudo, foram identificados alguns aspectos que potencialmente podem estar relacionados com a baixa recuperação bacteriana encontrada. As amostras fecais não foram testadas para enteropatógenos como ETEC, Campylobater spp, $Y$. enterocolitica, Providencia alcalifaciens, A. hydrophila, Giárdia lamblia, e portanto diarréias com essas etiologias não poderiam ser identificadas. O fato de aproximadamente $70,0 \%$ das crianças já estarem em uso de antibiótico no momento da coleta da amostra fecal, sem dúvida também interferiu no resultado das coproculturas. 18 Outro fato digno de nota foi o alto índice de antibioticoterapia (91,6\%). O IMIP é um hospital de referência, recebendo freqüentemente pacientes em estado grave e apresentando co-morbidades. Diante desse perfil é freqüente o uso de antimicrobianos, não significando, no entanto, que sua indicação esteja correta em todos os casos. As implicações negativas advindas do uso de antibióticos, especialmente nessa doença, devem fazer com que sempre se tenha uma reflexão cuidadosa quanto a sua utilização.

A Klebsiella $s p$. ESBL+ (extended-spectrum beta-lactamase) foi isolada em 33,3\% das amostras. Bactérias produtoras de ESBLs representam um problema universal.19 Elas têm sido responsáveis pela irrupção de numerosas infecções de difícil con- 
trole ao redor do mundo. 20 Entre essas, as Enterobacteriaceae ESBL + ocupam lugar de destaque em infecções da faixa pediátrica. ${ }^{21-25}$

As ESBLs são um conjunto de enzimas capazes de hidrolisar penicilinas, cefalosporinas de largo espectro e monobactâmicos. 22 São codificadas em genes localizados no cromossomo ou nos plasmídios. Os plasmídios podem ser transferidos intra e inter espécies bacterianas. Tal fato se reveste de grande importância quando se trata da transferência de ESBL entre as Enterobacteriaceae. ${ }^{20}$ A produção de ESBL pode estar associada à expressão de AmpC betalactamase, conferindo resistência aos aminoglicosídeos. Soma-se ainda o crescente numero de relatos da associação de ESBL à resistência a fluoroquinolonas. 22 Diante do alto perfil de resistência, a identificação de bactérias produtoras de ESBL é clinicamente relevante e indica a necessidade de apropriada antibioticoterapia. Atualmente os carbapenêmicos são as drogas de escolha. 19,20

As Klebsiellas isoladas nas amostras fecais apresentaram um alto perfil de resistência no antibiograma, sendo compatíveis com as cepas hospitalares catalogadas pela CCIH do IMIP. Conclui-se, portanto, que esses agentes colonizaram o trato gastrintestinal das crianças após o internamento. Esta colonização provavelmente se deu em um tempo curto, já que 50,0\% das culturas estavam positivas no terceiro dia de internamento. A colonização intestinal Klebsiella multirresistente é preocupante, pois a presença de bactérias nosocomiais na microflora intestinal é um fator de risco para infecção hospitalar, portanto para o aumento da morbimortalidade. 26

\section{Referências}

1. Bern C, Martines J, Zoysa I, Glass RI. The magnitude of the global problem of diarrhoeal disease: a ten-year update. Bull WHO. 1992; 70: 705-14.

2. Snyder JD, Merson MH. The magnitude of the global problem of acute diarrhoeal disease: a review of active surveillance data. Bull WHO. 1992; 60: 605-13.

3. WHO (World Health Organization) Diarrhoeal Disease Control Programme, CDD, 1984. Geneve; 1984.

4.Ministério da Saúde. Informações de saúde. Disponível em: http// www.datasus.gov.br. 2001 [2005 Set 19]

5. Oliva CAG, Palma D. Suporte nutricional nas diarréias aguda e persistente In: Barbieri D, Palma D. Gastroenterologia e nutrição. São Paulo: Atheneu; 2001 p. 259-69.

6. Silva GAP. Diarréia aguda e persistente In: Alves JGB, Ferreira OS, Maggi RS. Fernando Figueira Pediatria. Instituto Materno-Infantil de Pernambuco. 3. ed. Recife: Medsi; 2004.
Classicamente, a Klebsiella sp. é considerada parte da microbiota normal do intestino e não apresenta enteropatogenicidade. Contudo, alguns estudos vêm identificando cepas associadas à gastroenterite infecciosa.27,28 Além disso mecanismos enteropatogênicos tais como a produção de enterotoxinas termoestáveis 29 e a aderência celular que leva ao influxo descontrolado de cálcio no epitélio intestinal. 30

Além do potencial enteropatogênico, as Klebsiellas podem transferir plasmídios contendo o gene da ESBL para bactérias como E. coli, Yersinia, Serratia e Providencia, gerando sérios problemas no tratamento desses agentes.

As limitações apresentadas neste estudo, dificultaram um conhecimento mais aprofundado do perfil etiológico da diarréia na criança hospitalizada no IMIP. No entanto, os resultados revelaram um número preocupante de bactérias produtoras de ESBLs e, com base no que foi exposto acima, podese admitir que a presença de Klebsiella multirresistente no trato gastrointestinal tem implicação na persistência do episódio diarréico e em infecções hospitalares nas crianças internadas. Estes fatos podem estar associados ao aumento dos custos e da morbimortalidade dos pacientes.

\section{Agradecimentos}

Ao Instituto Materno Infantil Prof. Fernando Figueira, IMIP pelo suporte e ao Conselho Nacional de Desenvolvimento Científico e Tecnológico, CNPQ pela bolsa do Programa de Iniciação Científica.

7. Souza EC, Martinez MB, Taddei CR, Mukai L, Gilio AE, Racz ML, Silva L, Ejzenberg B, Okay Y. Perfil etiológico das diarréias agudas em crianças atendidas em São Paulo. J Pediatr. [Rio J] 2002; 78: 31-8.

8. Schnack FJ, Fontana LM, Barbosa PR, Meyer LS, Baillargeon CMM, Barichello T, Póvoa MM, Cavasini CE, Machado RLD. Enteropatógenos associados com diarréia infantil ( $<5$ anos de idade) em amostra da população da área metropolitana de Criciúma, Santa Catarina, Brasil. Cad Saúde Pública. 2003; 19: 1205-8.

9. Toporovski MS, Mimica I, Chieffi PP, Paschoalotti MA, Dias AM, Silva CB. Diarréia aguda em crianças menores de três anos de idade: recuperação de enteropatógenos nas amostras fecais de pacientes comparada à de grupo controle. J Pediatr. [Rio J] 1999; 75: 97-104. 
10. Huilan S, Zhen LG, Mathan MM, Mathew MM, Olarte J, Espejo R, Khin Maung U, Ghafoor, MA, Khan MA, Sami Z. Etiology of acute diarrhoea among children in developing countries: a multicentre study in five countries. Bull WHO. 1991; 69: 549-55.

11. Orlandi PP, Silva T, Magalhães GF, Alves F, Cunha RPA, Durlacher R, Silva LHP. Enteropathogens associated with diarrhoeal disease in infants of poor urban areas of Porto Velho, Rondônia: a preliminary study. Mem Inst Oswaldo Cruz. 2001; 96: 621-5.

12. Urbina D, Arzuza O, Young G, Parra E, Castro R, Puello M. Rotavirus type A and other enteric pathogens in stool samples from children whith acute diarrhea on the Colombian northern coast. Int Microbiol. 2003; 6: 27-32.

13. Guerrant RL, Hughes JM, Lima NL, Crane J. Diarrhea in developed and developing countries: magnitude, special setting, and etiologies. Rev Infect Dis. 1990;12 (Suppl 1): S41-S50.

14. Tomar BS. Intestinal infections. Indian J Pediatr. 2001; 68: S8-18.

15. Beaugerie L, Petit JC. Microbial-gut interactions in health and disease. Antibiotic-associated diarrhea. Best Prect Res Clin Gastroenterol. 2004; 18: 337-52.

16. IMIP (Instituto Materno Infantil Prof. Fernando Figueira). Núcleo de Epidemiologia. Relatório. Bol. IMIP. 2004.

17. Maraki S, Georgiladakis A, Tselentis Y, Samonis G. A 5year study of the bacterial pathogens associated with acute diarrhoea on the island of Crete, Greece, and their resistance to antibiotics. Eur J Epidemiol. 2003; 18: 85-90.

18. Chitkara YK. Limited value of routine stool cultures in patients receiving antibiotic therapy. Am J Clin Pathol. 2005; 123: 92-5

19. Paterson DL. Recommendation for treatment of severe infections caused by Enterobacteriaceae producing extendespectrum beta-lactamases (ESBLs). Clin Microbiol Infect. 2000; 6: 460-3.

20. Shah AA, Hasan F, Ahmed S, Hameed A. Extended-spectrum beta-lactamases (ESBLs): characterization, epidemiology and detection. Crit Rev Microbiol. 2004; 30: 25-32.
21. Otman J, Cavassin ED, Perugini ME, Vidotto MC. An outbreak of extende-spetrum beta-lactamase-producing Klebsiella species in a intensive care unit in Brazil. Infect Control Hosp Epidemiol. 2002; 23: 8-9.

22.Rupp ME, Fey PD. Extende spectrum betalactamase (ESBL)-producing Enterobacteriaceae: considerations for diagnosis, prevention and drug treatment. Drugs. 2003; 63: 353-65.

23. Ayan M, Kuzucu C, Durmaz R, Aktas E, Cizmeci Z. Analysis of three outbreaks due Klebsiella species in neonatal intensive care unit. Infect Control Hosp Epidemiol. 2003; 24: 495-500.

24. Krontal S, Leibovitz E, Greenwald-Maimon M, Fraser D, Dagan R. Klebsiella bacteremia in children in southern Israel. Infection. 2002; 30: 125-31.

25. Wu TL, Chia JH, Su LH, Kuo AJ, Chu C, Chiu CH. Dissemination of extended-spectrum beta-lactamaseproducing Enterobacteriaceae in pediatric intensive care units. J Clin Microbiol. 2003; 41: 4836-8.

26. Cali R, Marba S, Nowakonsk A, Tresoldi AT. Reduction in colonization and nosocomial infection by multiresistant bacteria in a neonatal unit after institution of educational measures and restrition in use of cephalosporins. Am J Infect Control. 2001; 29: 133-8.

27. Niyogi SK, Pal A, Mitra U, Dutta P. Enteroaggregative Klebsiella pneumoniae in association with childhood diarrhoea. Indian J Med Res. 2000; 112: 133-4.

28. Ananthan, Raju S, Alavandi S. Enterotoxigenicity of Klebsiella pneumoniae associated with childhood gastroenteritis in Madras, India. Jpn J Infect Dis. 1999; 52: 16-7.

29. Albano F, Thompson MR, Orrú S, Scaloni A, Musetta A, Pucci P, Guarino A. Structural and functional features of modified heat-stable toxins produced by enteropathogenic Klebsiella cells. Pediatr Res. 2000; 48: 685-90.

30. Pal A, Hoque KM, Niyogi SK, Ramamurthy T, Nair GB, Bhattacharya SK, Chakrabarti MK. Rise in free intracellular calcium in HeLa cells infected with aggregative Klebsiella pneumoniae strains isolated from cases of diarrhoea. Indian J Med Res. 2001; 113: 1-4.

Recebido em 15 de outubro de 2005

Versão final apresentada em 18 de janeiro de 2006

Aprovado em 19 de fevereiro de 2006 